\title{
BEHAVIOURAL ECONOMICS THEORY
}

\section{Masters of deviations, irrationalities, and biases}

\author{
Young Lee*
}

\section{Background}

\subsection{Understanding how we, Homo sapiens, really behave}

Based on the utility concept, traditional economics models were created by the premise of impeccably rational humans when making decisions. These classical models have assumed that normal people, Homo sapiens, would behave the same way that Homo economicus (economic person) exercises infinite rationalities and self-control for the best benefits of themselves (Thaler, 2000). Thus, they were unable to grasp the psychology or cognition of normal Homo sapiens who has flaws in their reasoning and uses heuristics, instinct, and emotions in decision-making instead of perfect logic to calculate probability for the best utility after exhausting all comparisons between pros and cons of economic options. Behavioural economists suggest that humans have bounded rationality, in which people make decisions based on various cognitive limitations (Simon, 1957). Thus, unlike the traditional utility economic models, the premise of BE builds upon understanding common cognitive biases, irrationalities, and deviations that normal people exhibit, which often drive them to make decisions that are not in their best interest or beneficial to them.

BE pays special attention to three aspects of human behaviours: use of immediate cognitive resources such as heuristics in decision-making, temporal aspect of judgments, and social influence on individual decision-making (Samson, 2014). Heuristics are mental shortcuts used to make fast and easy decisions under limited information and time (Gilovich, Griffin, \& Kahneman, 2002). Rule of thumb, educated guess, and trial and error are heuristics that people frequently rely on and exercise for quick decision-making. These are known to work well in general but also are subject to errors, especially in more complex situations (Sunstein, 2017). In many cases, heuristics are exercised based on previous experiences, easily available memory, and initially obtained information (Zhang \& Highhouse, 2018). When heuristics induce systematic errors in judgment, biases tend to occur. When examining common human biases, $\mathrm{BE}$ also brings attention to human evaluations and judgments that are susceptible to time and social context. BE acknowledges that people are more perceptive to the present time and are constantly influenced by the social context and norms, introducing a temporal dimension and a social dimension in addition to cognitive dimension to the depth of the theoretical framework (Samson, 2014).

*Corresponding author: young.lee@innovativeworkplaceinstitute.org 
The core ideas of BE have already been exercised in consumer-oriented fields such as marketing, advertising, and television game shows in practice before BE. However, the world-renowned Nobel Prize recipient in economics Thaler, along with Kahneman and Tversky, has developed theoretical frameworks and established BE as a recognised division of mainstream economics. By integrating cognitive psychology to economics, these behavioural economists intended to understand the way that human cognition really works in economic decision-making and discover the common cognitive biases underlying irrational behaviours. BE has been applied to various fields beyond economics and finance, including social psychology, organisational psychology, business management, human resources, politics, and crime science, to understand social and organisational psychology as well as to implement strategies for easy motivation of people towards desired options (Samson, 2017). Often, these discoveries in BE are used to develop strategies and solutions to prevent shortcomings of the natural cognitive process of decision-making in various fields, such as public policy, HR, and public health to name a few.

\subsection{Cognitive, temporal, and social biases of $B E$}

Among many common cognitive biases in decision-making discussed in BE, this chapter focuses on the ones more relevant and applicable to the workplace. While not an exhaustive list, these comprise status quo bias, loss aversion, optimism bias, overconfidence, planning fallacy, herd behaviour, social norm, and reciprocity. Due to the relevance between these topics, certain topics are explained together below: (1) status quo bias and loss aversion focusing on heuristics and biases; (2) optimism bias, overconfidence, and planning fallacy on the temporal dimension; and (3) herd behaviour, social norm, and reciprocity on the social dimension of BE.

\subsubsection{Status quo bias and loss aversion}

It is easy to observe people's propensity for maintaining the default or the same previous settings in various devices such as cell phones or computers without changing them. These behaviours often sustain even in the events of vast improvements for their comfort, health, productivity, and financial benefits by changing these settings. The status quo bias means the preference of no changes or remaining the same status as before even if it requires only little efforts or costs, or people are aware of the benefits from the changes (Samuelson \& Zeckhauser, 1988). Inertia and procrastination may be the drivers of this behaviour. However, people tend to resort to no changes in situations of too much cognitive thinking involved or highly uncertain consequences of new options (Dean, Kibris, \& Masatlioglu, 2017). According to Samuelson and Zeckhauser (1988), three main reasons for status quo bias are cognitive misperceptions, psychological commitment, and difficulty with rational evaluation when costs and/or uncertainty are involved. Uncertainty, especially, drives people to gravitate to already known safe methods and circumstances to avoid risks (see also Chapter 17 Evolutionary Psychology Theory). People also tend to regret more when the results are bad from their new actions than from no actions (Kahneman \& Tversky, 1982). This is due to people's innate negativity bias, in which they naturally place more emphasis on negative consequences than positive consequences of their decisions (Baumeister, Bratslavsky, Finkenauer, \& Vohs, 2001).

The negativity bias leads people to evaluate loss and gain unequally. People tend to perceive losses more regrettably than they appreciate the same amount of gains from a decision, called the loss aversion bias (Kahneman \& Tversky, 1979). According to the loss aversion bias, people tend to commit to the potential gain only when it doubles the potential loss (Samson, 2014). This means that people are not motivated enough to change or select a new option without 
sufficient incentives that outweigh the potential loss from the change. Due to this concern with loss, when information is presented in a negative (loss) frame instead of a positive (gain) frame, people may perceive the consequences more seriously (Meyerowitz \& Chaiken, 1987). An example would be ' $10 \%$ rate of operations failure' versus ' $90 \%$ rate of operations success'. This is called framing effect, referring to a tendency of people whose decisions are affected by how the information is presented to them (Plous, 1993). When exercising framing effect in practice, a caution is necessary as the effect can yield different outcomes among different age groups due to a higher susceptibility to the automatic affect heuristic among certain age groups with a declining cognitive capacity (Thomas \& Millar, 2011). In addition, persuasiveness via the gain-loss frame to encourage/discourage certain behaviours may result in unexpected/ unintended outcomes, depending on topics and circumstances (Baek \& Yoon, 2017). Lastly, ethical questions may rise with regard to influencing people's decisions by manipulating how information is presented and perceived.

\subsubsection{Optimism bias, overconfidence, and planning fallacy}

People's evaluations and judgments on gains and losses are time dependent. People are presentbiased, weighing the present time significantly heavier than the past. Due to this tendency, people focus more on their present emotions, experiences, and circumstances than on how their past events of similar incidents actually turned out. When people evaluate the probability of positive vs. negative consequences of an event, they tend to become more optimistic regardless of the past experiences, called the optimism bias (Samson, 2017). An example of the optimism bias is that people tend to believe that they are less likely to cause a car accident despite their radical driving habits. This bias occurs regardless of past experiences and abundant information readily available (Kahneman \& Tversky, 1973). The optimism bias can exhibit from both a positive incident (e.g. believing to live longer due to eating organic foods) and a negative incident (e.g. believing their unlawful conduct to be unnoticed). However, people tend to feel more optimistic in negative incidents (Gouveia \& Clarke, 2001).

The optimism bias leads people to be overconfident when evaluating their own capability. Overconfidence becomes problematic when people overrate their performance and commit to certain plans above their true ability, warranting frequent failures to adhere to the original plans. Overconfidence is typically measured by overestimation, overplacement, and overprecision (Moore \& Healy, 2008). According to Moore and Healy (2008), people tend to falsely believe that their ability and performance are better than they actually are (overestimation), their ability and performance are better than others (overplacement), and their knowledge or information is more accurate than it really is (overprecision). Both optimism and overconfidence biases drive people to commit to planning fallacy that people underestimate time, cost, and risks (Lovallo \& Kahneman, 2003). The important aspect of planning fallacy is that this tendency occurs not because of lack of information available from the past failures in similar circumstances (Kahneman \& Tversky, 1973). Potential reasons for this tendency may be the inability to recognise the similarities between circumstances or comparing the circumstance to non-equivalent circumstances (Kahneman \& Tversky, 1979).

\subsubsection{Herd behaviour, social norm, and reciprocity}

$\mathrm{BE}$ focuses on the concept of herd behaviour to understand how individuals are affected by other people's opinions and social trends in forming their own opinions and making decisions. Instead of being independent decision makers, people, as social animals, tend to conform 
within the group that they belong to. Herd behaviour can be as innocent as trying to eat the same healthy foods as colleagues eat or as irrational as toilet paper stockpiling seen during the COVID-19 pandemic in early 2020 that was motivated by collective irrationality of fear and uncertainty. Social norms play a significant role in forming herd behaviours. Social norms are generally accepted and expected behaviours in a group or society (Dolan, Hallsworth, Halpern, King, \& Vlaev, 2010). The members in the group or society feel not only pressured to follow the shared social norms, but also feel shame or guilt when not conforming to those norms. Since social norms define what behaviours are appropriate within a group, they tend to be specific to the culture of the group.

Reciprocity is an interesting concept as a social norm since it emphasises a human nature beyond pure self-interest. Reciprocity is an in-kind exchange, not an economic exchange, responding to an action of others with the same kind of action, such as returning a favour (Samson, 2017). The famous old saying of 'an eye for an eye' is a direct example of reciprocity, showing how essential this concept is as a principle of social conduct deeply embedded in a human society. According to the reciprocity principle, people tend to be nicer and more cooperative when requested nicely. This cooperative propensity towards others is called positive reciprocity while the retaliatory behaviour in 'an eye for an eye' is called negative reciprocity. Reciprocity has been greatly examined in people's behaviours with tax compliance, voting, and fundraising (Malmendier, te Velde, \& Weber, 2014). While a small percentage of people exhibit no concept of reciprocity by acting solely based on pure self-interest, people in general conduct themselves per reciprocity in a society. Due to this reason, such topics as incentives and voluntary cooperative reciprocity, reciprocal behaviours and organisational outcomes, and incivility and retaliatory reciprocity have become of particular interest in the workplace.

\section{Applicability to workplace studies}

Since theories in economics are closely tied with business management, topics related to BE have been actively discussed in organisational management. Workplace policies and HR practices have, especially, sought strategies and tactics in BE to encourage desired behavioural changes within the organisation. These behaviours vary, including energy saving, healthier habits, job performance, or compliance to ethics (Ilieva \& Drakulevski, 2018). This adoption in business management was to take advantage of low to no cost associated with $\mathrm{BE}$ implications such as utilising negative framing by changing wording in a message. The majority of earlier adopters of BE in the built environment side of the workplace were in occupational health and safety, where the physical environment of the workplace could cause serious illnesses and injuries if not intuitive or straightforward to employee heuristics and cognitive procedural limitations (Seabury, Reville, Rhodes, \& Boden, 2005). Recently, workplace designers, facility managers, and workplace strategists have started recognising the potential of BE as a framework to facilitate workplace health and wellbeing (Lee, 2019). Expounding upon the aforementioned biases related to three dimensions of BE, this section further discusses the relevance of them to the workplace.

\subsection{Status quo bias and loss aversion}

A good example of the status quo bias in the workplace is maintaining the same environmental settings already in place, instead of changing them to optimise the environment to respond to the fluctuating external stimuli (see Figure 18.1). For instance, a reason for imbalance in daylight penetration into the workplace is due to people's inertia behaviour - once they close the shades to block out too much glare from daylight in the morning, they leave the window shades closed 
later in the day even if there is not enough daylight in their workplace (Steverson, 2017). Inertia behaviours, persisting to existing conditions and functions, are harmless in general but become problematic when the current conditions and functions are inefficient (Polites \& Karahanna, 2012). While the previous example is actively decided by individuals as a choice of no change/ action, many other decisions in the workplace are made for individuals by others as defaults, and individuals passively accept them ( $\mathrm{Lu} \&$ Xie, 2014). Office layouts and desk locations are decided by designers and facility managers, computer default settings by IT, and defaults in retirement account options by HR. Mandating a new change, without understanding the keen relationship between the status quo bias and cognitive misperceptions, can frequently end up as a failure in persuading employees to adopt a new change (Jasperson, Carter, \& Zmud, 2005). In providing resolutions for the status quo bias and inertia behaviours, some researchers focus on choosing the default options for the best interest of employees or utilising framing effect to direct them to more desirable decisions for their own interest. Others focus on how to promote individual competency in decision-making. For instance, Lu and Xie (2014) highlighted that the status quo bias could be mediated by evaluating gains and losses of a change with a more balanced set of queries and listing gains before losses to intervene with the negativity bias and the loss aversion bias (see Section 5 for these two approaches). While not a BE strategy, participatory design, utilised in architectural and workplace design integrating employees' suggestions for their own workspaces and workstyles to the overall workplace planning, can provide opportunities for employee involvement in decision-making, instead of forcing them to be passive adopters.

The status quo bias accelerates under the circumstances of uncertainty and difficulty with accurately judging gains and losses from a choice. These situations are the particular concerns of occupational safety and health professionals. This is because worker capability of collecting and processing information on risks is critical in these situations to prevent workplace injuries and reduce workers' compensation (Seabury et al., 2005). In this regard, many researchers focus on two issues: (1) cognitive process and individual biases in perceiving risks and deciding a choice such as overestimating vs. underestimating risks and (2) cost-benefit analysis of workplace safety

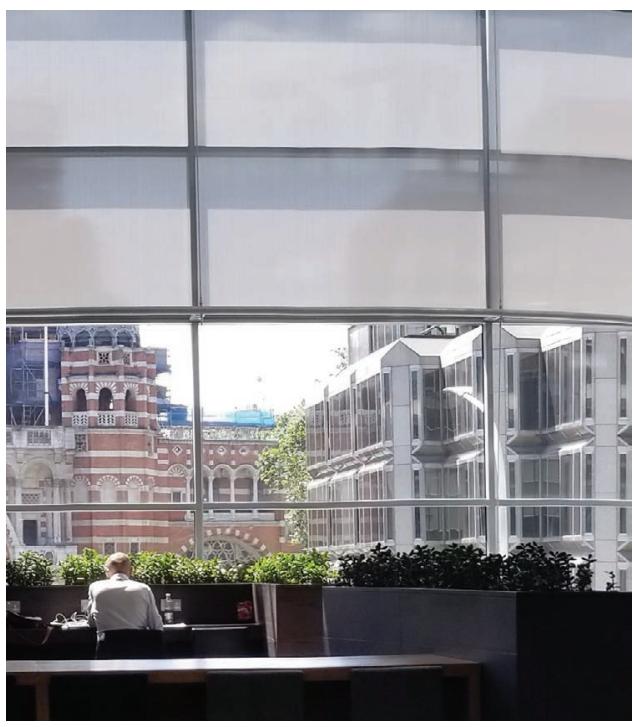

Figure 18.1 Window shades half closed all day without changes to control the amount of daylight 
to understand the comprehensive evaluation between costs and benefits. Cost-benefit analysis is also often used to understand at which costs people are willing to accept a new change, examining the degree of loss aversion between the willingness to pay and the willingness to accept an alternative option (Dauth \& Haller, 2020). With the recent workplace health and wellbeing trend, people's tendency of the status quo and inertia habits, such as prolonged sitting, has become a further concern (Das et al., 2016). To break up people's status quo tendency to promote workplace health and wellbeing, it is important to improve spatial and environmental elements and provide alternative options to promote physical movement. In addition, automated controls can provide necessary adjustments for constantly fluctuating environmental factors, such as daylight, temperature, or indoor air quality, without cumbersome human interventions throughout a day.

\subsection{Optimism bias, overconfidence, and planning fallacy}

Optimism, generally harmless, becomes a problematic issue in the workplace when it is accompanied by overconfidence. This is because overconfidence leads to inaccurate judgments and projections in organisational planning. The majority of research in overconfidence focuses on overestimation. Researchers have discovered that people tend to underestimate their ability when tasks are easy or they are well experienced with the tasks, but overestimate it when tasks are rather difficult (Michailova \& Katter, 2014). This is known as the hard-easy effect in cognitive psychology (Lichtenstein \& Fischhoff, 1977). Experiences are also associated with overconfidence in a similar manner to the hard-easy effect: people tend to be overconfident when less experienced with the business type (Hayward, Shepherd, \& Griffin, 2006). Many studies confirm people's tendency with overplacement (Beer \& Hughes, 2010). Known as the better-than-average belief, overplacement is prevalent despite objective performance standards available in organisations (Benoît, Dubra, \& Moore, 2015). A wishful thinking of expecting to be better than others may lead people to the overplacement belief. Overprecision, judgmental overconfidence, is most widespread but least studied and understood among the three types of overconfidence in organisational behaviours (Moore \& Schatz, 2017). While overprecision may be derived from a lack of knowledge or experiences, studies also show that a higher level of accuracy in business is associated with higher confidence in the knowledge (Ilieva, Brudermann, \& Ljubomir, 2018). Ilieva et al. (2018) also found that people making decisions alone, highly relying on their own knowledge and judgment without consulting others, tend to be overconfident. However, overconfidence is not always negative in the workplace. Such an attitude can lead people to be more innovative and persuasive, not to mention increased subjective wellbeing about one's own self.

The attitude of solely relying on only one source of information can easily lead to planning errors in organisations. Since people are unaware of the full scope of situations, they tend to underestimate the probability of obstacles and risks. Planning fallacy can happen in underestimations of various resources. An infamous example is a construction time and cost underestimation in Sydney Opera House, in which the six-year project with an initial cost of \$7 million in 1957 ended up opening in 1973 with an over budget of $\$ 102$ million (Buehler, Griffin, \& Ross, 2002). It is argued that over $50 \%$ of the projects are underestimated in budget (Love, Ika, \& Sing, 2019). Time underestimations can also range from 30\% less time than the actual time required for easy to moderate projects to $50 \%$ for complex projects as shown in Microsoft's internal analysis of their delayed projects (Beshears \& Gino, 2015). Planning fallacy is shown in many mega structures and novel projects such as the London Wembley Stadium, in which the initial projection of time and cost was difficult due to no precedent cases and the complexity of the scope. However, planning fallacy tends to exhibit even when the information on precedents is available. This is because 
people take an inside view where they focus on the uniqueness of the task/project and disregard past experiences, as opposed to an outside view where they contemplate other factors when predicting time and budget to complete a task/project (Buehler et al., 2002). Since planning fallacy is persistent regardless of precedent information and outside views available, it may be wise for organisations to embrace the bias and focus on modifying the projection of required resources by establishing a standardised procedure of adding safety margins or incorporating other available information in determining necessary resources. Examining past projects is a good resolution to planning fallacy by understanding typical estimation errors within the organisation and adding more accurate safety margins for future project estimations.

\subsection{Herd behaviour, social norm, and reciprocity}

The concept of social norms has recently been utilised as a cost-effective approach to motivating people to engage in behavioural changes for sustainability and health promotion in the workplace. For instance, presenting one's energy consumption trend compared to others stimulates her/his motivation to stick to the similar trend of others' energy use (Allcott, 2011). Worksite health and wellness promotion programs are also known to be more effective in sustaining healthy behavioural changes when accompanied with changes in workplace norms (Carnethon et al., 2009). In addition, utilising descriptive social norm messages has shown to promote daily healthy behaviours by indicating how other people commit to healthy behaviours. Displaying signs near elevators to encourage stair climbing instead of using elevators (see Figure 18.2) showed nearly $50 \%$ of people switching to using stairs from elevators (Burger \& Shelton, 2011). Displaying posters with a social norm message on vegetable choice by others also increased vegetable selection at workplace restaurants (Thomas et al., 2017). This is because people consider other people's behaviours as a guide in deciding their behaviours, which explains why people within the same social group such as family often exhibit the same dietary preferences. While simple methods as social norm messages can influence healthy behaviours, promoting a healthy lifestyle at work is more complex and requires more than simple BE tactics. In order to change and promote workplace norms related to health and wellbeing, a combination of supports from various disciplines is necessary. This is because solving a complex problem requires a multidimensional approach since a singular approach has failed too many times. To make health promotion a social norm in the workplace, supports in physical environment, policy, and educational programmes would be simultaneously necessary (Lee, 2019).

Reciprocity in the workplace, both cooperative and retaliatory, between the organisation and employees or among employees is of particular interest to organisational behavioural researchers. People have shown a tendency to return a favour by working harder in response to a company paying a higher or fair wage (Akerlof, 1982). This kind of behaviour, called gift exchange, is often examined in terms of employee willingness to work harder for non-monetary gifts such as holidays. Unlike many economists' belief that non-monetary gifts are less efficient than money, non-monetary gifts have shown to be of higher value than are monetary gifts (Kube, Maréchal, \& Puppe, 2012). Kube et al. (2012) also suggested that employees may reciprocate a company's kind offer with various options beyond simple productivity, including reduced absenteeism and higher retention and loyalty. Retaliatory reciprocity is also frequently observed in the workplace. Employee thefts of company properties have shown to increase after a wage decrease decision by the company (Giacalone \& Greenberg, 1997). Commonly observed personal retaliatory behaviours against other colleagues range from active retaliatory behaviours (e.g. sabotaging one's work) to passive ones (e.g. not coming to work). While the severity level tends to match between misconducts and retaliatory reactions (e.g. mild misconducts followed 


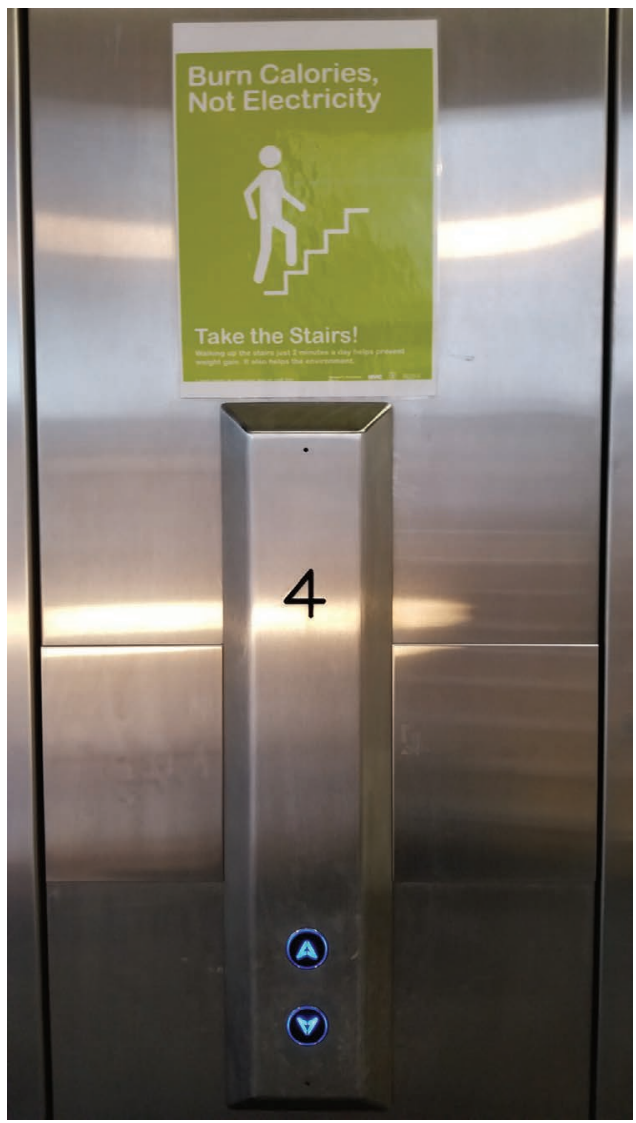

Figure 18.2 A descriptive message encouraging to use stairs instead of elevators

by mild retaliatory reactions and severe misconducts by severe retaliatory responses), individual personality differences exist (e.g. severe retaliatory reactions for mild misconducts or mild retaliatory reactions for severe misconducts) (Greco, Whitson, O’Boyle, Wang, \& Kim, 2019). Furthermore, most people, up to $60 \%$, tend to choose reciprocal reactions, but $20 \%$ to $30 \%$ of them act in pure self-interest (Gächter \& Falk, 1999). While individual personality differences affect the decision of reciprocal responses, organisational cultures also have a tremendous impact on deviant behaviours (Di Stefano, Scrima, \& Parry, 2019). Such deviant and retaliatory behaviours can harm not only interpersonal relationships but also organisational efficiency, function, and morale. It is important to prevent undesirable retaliatory behaviours, but also reward collaborative reciprocal behaviours with proper policy implications.

\section{Methodology/research approach}

Many studies applying BE theories and biases to workplace-related topics use research methods available in behavioural science. Researchers examine how a choice/decision is made, focusing on emotional, cognitive, temporal, and social dimensions in human biases and decision-making processes. Or, they investigate the consequences of decisions or behaviours committed based on these biases. The studies focusing on decision-making processes trace steps of decision-making, utilising various 
techniques, including computational modelling and simulations in more recent studies (Zhang \& Highhouse, 2018). When examining which choice/decision is made, observations have frequently been utilised to understand specific choice behaviours. These studies often compare different scenarios to see changes in choice behaviours. Some researchers investigate behavioural patterns in individuals, while others in the issues of organisational behaviours and associated impacts on organisations.

Surveys are also heavily utilised to understand choice behaviours by directly asking the participants. Many overconfidence studies measure participants' estimates as self-assessment. The self-reported results can be analysed between people's various ratings on their own subjective capability or by comparing their subjective ratings to the actual data to understand the gap between these two. Lastly, secondary or publicly available data can be utilised to understand habitual behavioural patterns within or across organisations. For future studies, it is recommended to strengthen studies incorporating subjective measures with further standardised measurements due to the weaknesses associated with subjective measures. Studies also need to be conducted in more controlled circumstances to be able to offer more consistent suggestions to other organisations. Otherwise, these studies become anecdotal stories only specific to an organisation, since human biases are time- and social context-dependent.

\section{Limitations}

$\mathrm{BE}$ is criticised for overly focusing on understanding the limitations of human cognition and deviated behaviours from the traditional economic theories, not the underlying reasons why we behave the way we behave. Since it is not able to answer the fundamental reasons behind our behaviours, it has difficulty of generalisation and consistent application to various subjects. In addition, there is a cultural difference in how reasoning is defined and accepted as being appropriate (Etzioni, 2011). Since, in some cultures, religious or social norms more heavily affect reasoning, it may be difficult to expect the same outcomes observed in other cultures. Ethics has always been questioned in exercising BE. It can easily manipulate our perception with an intent of taking advantage of our natural weakness for undesired outcomes to us by those imposing BE on us. Thus, BE should only be used under three conditions: transparency, easy to opt out, and only employed for the benefit of users (Thaler \& Sunstein, 2008). BE research in the workplace often utilises subjective ratings, exhibiting a methodological weakness. For instance, evaluating overplacement by self-assessment can be problematic due to ambiguous performance standards in people's subjective minds, since people may define differently what work performance means and what to consider to estimate their own subjective ability (Meikle, Tenney, \& Moore, 2016). How questions are structured and worded also tend to influence people's answers in surveys and interviews. In addition to the methodological limitations, certain topics and biases have shown mixed results in different circumstances. This may be due to human biases being context-dependent.

\section{Theory relevance to practice}

$\mathrm{BE}$ has the potential to offer workplace professionals a consistent framework to (1) understand limitations in human decision-making; (2) implement plans to support the natural cognitive process as well as prevent cognitive shortcomings; and (3) evaluate policies, environments, and cultures of organisations to encourage positive behaviours and resolve conflicts between individuals. In general, motivating people towards more desired directions can be done in two approaches. One way is to structure and present desired choices to easily appeal to heuristics, intuitions, and emotions. The other way is to create mechanisms and tools to encourage a concerted effort to deliberate for the best decisions. The former is called choice architecture, 
and this approach of motivating people to choose desired decisions is called nudging (Thaler \& Sunstein, 2008) (see also Chapter 19 on nudging theory). The latter approach is called boosting (Grüne-Yanoff \& Hertwig, 2016).

However, it may not be straightforward in practice how to implement strategies to overcome our own limitations and become wise decision makers in the workplace. We humans are complex beings whose perceptions and judgments are constantly influenced by our physical and social environments. Thus, we should not assume that perfect predictions of human behaviours and behavioural modelling are possible to offer the one-size-fits-all type of strategy for workplace behaviours. Instead, we should focus on understanding our own cognitive limitations to implement workplace strategies that will lead to actual behavioural changes. In doing so, we have to be mindful of two things to be successful: individual variation and multidimensional approach. We are born with natural variations within a spectrum (e.g. introverted vs. extroverted or hypersensitive vs. hyposensitive). Certain personality traits tend to be more prominently associated with particular behavioural patterns than others (see also Chapter 10 Temperament Theory). However, personality traits alone cannot predict our behaviours. We are continuously influenced by physical and social environments while shaping new opinions and experiences, not to mention our own capacity to learn and grow to become a more competent decision maker. This brings up the importance of a multidimensional approach. A multidimensional approach is advantageous in (1) simultaneously addressing various facets of a circumstance and (2) bringing diverse strategies that appeal to individuals with various preferences and cognitive processes. When planning behavioural changes in the workplace, it is necessary to watch out for inadvertent consequences of complex human psychologies such as the licensing effect, in which people justify their undesirable behaviour after doing a desired behaviour such as eating junk food after exercising. Furthermore, it is always wise to target longer-term outcomes for sustainable behavioural changes, as there is a tendency for people to resort back to old habits once short-term interventions are finished, as shown in the yo-yo effect.

\section{Further reading}

- Hertwig, R., \& Grüne-Yanoff, T. (2017). Nudging and boosting: Steering or empowering good decisions. Perspectives on Psychological Science, 12(6), 973-986.

- Hoffman, E., McCabe, K. A., \& Smith, V. L. (1998). Behavioral foundations of reciprocity: Experimental economics and evolutionary psychology. Economic Inquiry, 35(3), 335-352.

- Hollingworth, C., \& Barker, L. (2016). How to apply behavioural science with success: Learning from application around the world. In A. Samson (Ed.), The behavioral economics guide 2016 (pp. 30-36). Retrieved from https://www.behavioraleconomics.com

- Ilieva, V., \& Drakulevski, L. (2018). Applying behavioral economics insights at the workplace. Journal of Human Resource Management, 21(2), 40-48.

- Lee, Y. (2019). Workplace health and its impact on human capital: Seven key performance indicators of workplace health. In O. Korhan (Ed.), Indoor environment and health (pp. 1-29). London: IntechOpen. www.intechopen.com/books/indoor-environment-and-health/work place-health-and-its-impact-on-human-capital-seven-key-performance-indicators-ofworkplace-healt

\section{References}

Akerlof, G. A. (1982). Labor contracts as partial gift exchange. Quarterly Journal of Economics, 97, 543-569. https://doi.org/10.2307/1885099 
Allcott, H. (2011). Social norms and energy conservation. Journal of Public Economics, 95(5), $1982-2095$. https://doi.org/10.1016/j.jpubeco.2011.03.003

Baek, T. H., \& Yoon, S. (2017). Guilt and shame: Environmental message framing effects. Journal of Advertising, 46(3), 440-453. https://doi.org/10.1080/00913367.2017.1321069

Baumeister, R. F., Bratslavsky, E., Finkenauer, C., \& Vohs, K. D. (2001). Bad is stronger than good. Review of General Psychology, 5, 323-370.

Beer, J. S., \& Hughes, B. L. (2010). Neural systems of social comparison and the "above-average" effect. Neuroimage, 49(3), 2671-2679. https://doi.org/10.1016/j.neuroimage.2009.10.075

Benoit, J. P., Dubra, J., \& Moore, D. A. (2015). Does the better-than-average effect show that people are overconfident?: Two experiments. Journal of the European Economic Association, 13(2), 293-329. https:// doi.org/10.1111/jeea.12116

Beshears, J., \& Gino, F. (2015, May). Leaders as choice architects. Harvard Business Review.

Buehler, R., Griffin, D., \& Ross, M. (2002). Inside the planning fallacy: The causes and consequences of optimistic time predictions. In T. Gilovich, D. Griffin, \& D. Kahneman (Eds.), Heuristics and biases: The psychology of intuitive judgment (pp. 251-270). Cambridge: Cambridge University Press.

Burger, J. M., \& Shelton, M. (2011). Changing everyday health behaviors through descriptive norm manipulations. Social Influence, 6(2), 69-77. https://doi.org/10.1080/15534510.2010.542305

Carnethon, M., Whitsel, L. P., Franklin, B. A., Kris-Etherton, P., Milani, R., Pratt, C. A., \& Wagner, G. R. (2009, October 27). Worksite wellness programs for cardiovascular disease prevention. Circulation, 120(17), 1725-1741.

Das, B. M., Mailey, E., Murray, K., Phillips, S. M., Torres, C., \& King, A. C. (2016). From sedentary to active: Shifting the movement paradigm in workplaces. Work, 54(2), 481-487. https://doi. org/10.3233/WOR-162330

Dauth, W., \& Haller, P. (2020). Is there loss aversion in the trade-off between wages and commuting distances? Regional Science and Urban Economics, 83(C). https://doi.org/10.1016/j.regsciurbeco.2020.103527

Dean, M., Kibris, O., \& Masatlioglu, Y. (2017). Limited attention and status quo bias. Journal of Economic Theory, 169(C), 93-127. https://doi.org/10.1016/j.jet.2017.01.009

Di Stefano, G., Scrima, F., \& Parry, E. (2019). The effect of organizational culture on deviant behaviours in the workplace. International Journal of Human Resource Management, 30(17), 2482-2503. https://doi. org/10.1080/09585192.2017.1326393

Dolan, P., Hallsworth, M., Halpern, D., King, D., \& Vlaev, I. (2010). MINDSPACE: Influencing behaviour through public policy. London: Cabinet Office.

Etzioni, A. (2011). Behavioral economics: Next steps. Journal of Consumer Policy, 34(3), 277-287. https:// doi.org/10.1007/s10603-011-9160-y

Gächter, S., \& Falk, A. (1999). Reputation or reciprocity? Zurich, Germany: Institute for Empirical Research in Economics at University of Zurich.

Giacalone, R., \& Greenberg, J. (1997). Antisocial behavior in organizations. Thousand Oaks, CA: Sage Publications.

Gilovich, T., Griffin, D., \& Kahneman, D. (2002). Heuristics and biases: The psychology of intuitive judgment. Cambridge: Cambridge University Press.

Gouveia, S. O., \& Clarke, V. (2001). Optimistic bias for negative and positive events. Health Education, 101(5), 228-234. https://doi.org/10.1108/09654280110402080

Greco, L. M., Whitson, J. A., O’Boyle, E., Wang, C. S., \& Kim, J. (2019). An eye for an eye? A meta-analysis of negative reciprocity in organizations. Journal of Applied Psychology, 104(9), 1117-1143. https://doi.org/ 10.1037/apl0000396

Grüne-Yanoff, T., \& Hertwig, R. (2016). Nudge versus boost: How coherent are policy and theory? Minds E Machines, 26(2016), 149-183. https://doi.org/10.1007/s11023-015-9367-9

Hayward, M., Shepherd, D. A., \& Griffin, D. (2006). A Hubris theory of entrepreneurship. Management Science, 52(2), 160-172. https://doi.org/10.1287/mnsc.1050.0483

Ilieva, V., Brudermann, T., \& Ljubomir, D. (2018). "Yes, we know!” (Over)confidence in general knowledge among Austrian entrepreneurs. PLoS One, 13(5), 1-15. https://doi.org/10.1371/journal.pone.0197085

Ilieva, V., \& Drakulevski, L. (2018). Applying behavioral economics insights at the workplace. Journal of Human Resources Management, 21(2), 40-48.

Jasperson, J. S., Carter, P. E., \& Zmud, R. W. (2005). A comprehensive conceptualization of post-adoptive behaviors associated with information technology enabled work systems. MIS Quarterly, 29(3), 525-557.

Kahneman, D., \& Tversky, A. (1973). On the psychology of prediction. Psychological Review, 80(4), 237251. https://doi.org/10.1037/h0034747 
Kahneman, D., \& Tversky, A. (1979). Prospect theory: An analysis of decision under risk. Econometrica, 47(2), 263-291. https://doi.org/10.2307/1914185

Kahneman, D., \& Tversky, A. (1982). The psychology of preference. Scientific American, 246(1), $160-173$. https://doi.org/10.1038/scientificamerican0182-160

Kube, S., Maréchal, M. A., \& Puppe, C. (2012). The currency of reciprocity: Gift exchange in the workplace. American Economic Review, 102(4), 1644-1662. https://doi.org/10.1257/aer.102.4.1644

Lee, Y. (2019). Workplace health and its Impact on human capital: Seven key performance indicators of workplace health. In O. Korhan (Ed.), Indoor environment and health (pp. 1-29). London: IntechOpen. Retrieved from https://www.intechopen.com/books/indoor-environment-and-health/workplacehealth-and-its-impact-on-human-capital-seven-key-performance-indicators-of-workplace-healt

Lichtenstein, S., \& Fischhoff, B. (1977). Do those who know more also know more about how much they know? Organizational Behavior and Human Decision Processes, 20(2), 159-183. https://doi. org/10.1016/0030-5073(77)90001-0

Lovallo, D., \& Kahneman, D. (2003). Delusions of success: How optimism undermines executives' decisions. Harvard Business Review, 56-63.

Love, P., Ika, L. A., \& Sing, M. (2019). Does the planning fallacy prevail in social infrastructure projects? Empirical evidence and competing explanations. In IEEE transactions on engineering management (pp. 1-15). San Mateo, CA: Institute of Electrical and Electronics Engineers.

Lu, J., \& Xie, X. (2014). To change or not to change: A matter of decision maker's role. Organizational Behavior and Human Decision Processes, 124(1), 47-55. https://doi.org/10.1016/j.obhdp.2013.12.001

Malmendier, U., te Velde, V. L., \& Weber, R. A. (2014). Rethinking reciprocity. Annual Review of Economics, 6, 849-874. https://doi.org/10.1146/annurev-economics-080213-041312

Meikle, N. L., Tenney, E. R., \& Moore, D. A. (2016). Overconfidence at work: Does overconfidence survive the checks and balances of organizational life? Research in Organizational Behavior, 36, $121-134$. https://doi.org/10.1016/j.riob.2016.11.005

Meyerowitz, B. E., \& Chaiken, S. (1987). The effect of message framing on breast self-examination attitudes, intentions, and behavior. Journal of Personality and Social Psychology, 52(3), 500-510. https://doi. org/10.1037/0022-3514.52.3.500

Michailova, J., \& Katter, J. (2014). Quantifying overconfidence in experimental finance. International Journal of Behavioural Accounting and Finance, 4(4), 351-367. https://doi.org/10.1504/IJBAF.2014.067629

Moore, D. A., \& Healy, P. J. (2008). The trouble with overconfidence. Psychological Review, 115(2), 502517. https://doi.org/10.1037/0033-295X.115.2.502

Moore, D. A., \& Schatz, D. (2017). The three faces of overconfidence. Social and Personality Psychology Compass, 11(8), 1-12. https://doi.org/10.1111/spc3.12331

Plous, S. (1993). The psychology of judgment and decision making. ISBN 978-0-07-050477-6. New York: McGraw-Hill.

Polites, G., \& Karahanna, E. (2012). Shackled to the status quo: The inhibiting effect of incumbent system habit, switching costs, and inertia on new system acceptance. MIS Quarterly, 36(1), 21-42. https://doi. org/10.2307/41410404

Samson, A. (2014). An introduction to behavioral economics. In A. Samson (Ed.), The behavioral economics guide 2014 (pp. 1-12). Behavioral Economics Group. Retrieved from www.behavioraleconomics.com

Samson, A. (2017). Behavioral economics: Expanding boundaries. In A. Samson (Ed.), The behavioral economics guide 2017 (pp. 1-17). Behavioral Economics Group. Retrieved from www.behavioraleconomics.com

Samuelson, W., \& Zeckhauser, R. J. (1988). Status quo bias in decision making. Journal of Risk and Uncertainty, 1, 7-59. https://doi.org/10.1007/BF00055564

Seabury, S. A., Reville, R. T., Rhodes, H. J., \& Boden, L. I. (2005). How can behavioral economics inform research on workplace injuries? In K. Roberts, J. F. Burton, \& M. M. Bodah, Workplace injuries and diseases: Prevention and compensation (pp. 219-252). Kalamazoo, MI: W.E. Upjohn Institute for Employment Research.

Simon, H. A. (1957). Models of man. New York: John Wiley.

Steverson, B. (2017). Circadian light for your health. Chicago, IL: US GSA Office of Federal High-Performance Buildings.

Sunstein, C. (2017). Don't tell me what I can't do: On the intrinsic value of control. In A. Samson (Ed.), The behavioral economics guide 2017 (pp. V-XII). Retrieved from https://www.behavioraleconomics.com.

Thaler, R. (2000). From Homo economicus to Homo sapiens. Journal of Economic Perspectives, 14(1), $133-141$. https://doi.org/10.1257/jep.14.1.133 


\section{Behavioural economics theory}

Thaler, R., \& Sunstein, C. (2008). Nudge: Improving decisions about health, wealth and happiness. New Haven, CT: Yale University Press.

Thomas, A. K., \& Millar, P. R. (2011). Reducing the framing effect in older and younger adults by encouraging analytic processing. The Journals of Gerontology Series B: Psychological Sciences and Social Sciences, 67B (2), 139-149. https://doi.org/10.1093/geronb/gbr076

Thomas, J. M., Ursell, A., Robinson, E. L., Aveyard, P., Jebb, S. A., Herman, C. P., \& Higgs, S. (2017). Descriptive social norm to increase vegetable selection in workplace restaurant settings. Health Psychology, 36(11), 1026-1033. https://doi.org/10.1037/hea0000478

Zhang, D. C., \& Highhouse, S. (2018). Judgment and decision making in the workplace. In D. S. Ones, N. Anderson, C. Viswesvaran, \& H. K. Signangil (Eds.), The SAGE handbook of industrial, work E organizational psychology: Personnel psychology and employee performance (pp. 611-633). London, UK: Sage Publication Ltd. 